\title{
BMJ Global Health Law, criminalisation and HIV in the world: have countries that criminalise achieved more or less successful pandemic response?
}

\author{
Matthew M Kavanagh (D) ,, ${ }^{1,2}$ Schadrac C Agbla, ${ }^{3,4}$ Marissa Joy, ${ }^{2}$ Kashish Aneja, ${ }^{2,5}$ \\ Mara Pillinger, ${ }^{2}$ Alaina Case, ${ }^{6}$ Ngozi A Erondu (D) , ${ }^{2}$ Taavi Erkkola, ${ }^{7}$ \\ Ellie Graeden (1) ${ }^{6,8}$
}

\begin{abstract}
To cite: Kavanagh MM, Agbla SC, Joy M, et al. Law, criminalisation and HIV in the world: have countries that criminalise achieved more or less successful pandemic response?BMJ Global Health 2021;6:e006315. doi:10.1136/ bmjgh-2021-006315
\end{abstract}

Handling editor Seye Abimbola Accepted 14 July 2021
Received 14 May 2021

\section{ABSTRACT}

How do choices in criminal law and rights protections affect disease-fighting efforts? This long-standing question facing governments around the world is acute in the context of pandemics like HIV and COVID-19. The Global AIDS Strategy of the last 5 years sought to prevent mortality and HIV transmission in part through ensuring people living with HIV (PLHIV) knew their HIV status and could suppress the HIV virus through antiretroviral treatment. This article presents a cross-national ecological analysis of the relative success of national AIDS responses under this strategy, where laws were characterised by more or less criminalisation and with varying rights protections. In countries where same-sex sexual acts were criminalised, the portion of PLHIV who knew their HIV status was $11 \%$ lower and viral suppression levels $8 \%$ lower. Sex work criminalisation was associated with $10 \%$ lower knowledge of status and $6 \%$ lower viral suppression. Drug use criminalisation was associated with $14 \%$ lower levels of both. Criminalising all three of these areas was associated with approximately $18 \%-24 \%$ worse outcomes. Meanwhile, national laws on non-discrimination, independent human rights institutions and genderbased violence were associated with significantly higher knowledge of HIV status and higher viral suppression among PLHIV. Since most countries did not achieve 2020 HIV goals, this ecological evidence suggests that law reform may be an important tool in speeding momentum to halt the pandemic.

\section{Check for updates}

(C) Author(s) (or their employer(s)) 2021. Re-use permitted under CC BY-NC. No commercial re-use. See rights and permissions. Published by BMJ.

For numbered affiliations see end of article.

Correspondence to Dr Matthew M Kavanagh; matthew.kavanagh@ georgetown.edu

\section{INTRODUCTION}

Pandemic diseases like HIV present a significant challenge for public health. When neither a cure nor a vaccine is available, halting the pandemic requires a mix of biomedical and social interventions aimed at averting death and reducing new infections. The legal and policy environment in a given national context has been identified as a determinant of health outcomes as it shapes vulnerability to disease, behaviours

\section{Summary box}

- Countries around the world, across economic and geographical boundaries, have taken different approaches to the application of criminal law to samesex sexual activity, sex work and drug use-with most taking a partially or fully criminalising legal approach in one or more of these areas.

- Globally agreed HIV goals for 2020 focused on ensuring most people living with HIV were aware of their HIV status and had suppressed the HIV virus through effective antiretroviral treatment.

- AIDS pandemic response was less successful in countries that criminalised same-sex sexual acts, sex work and drug use individually and in combination than in those that did not-achieving significantly lower levels of HIV status knowledge and HIV viral suppression.

- Countries with clear laws advancing nondiscrimination, human rights institutions and gender-based violence response had significantly better knowledge of HIV status and viral suppression rates.

- This analysis suggests a new Global AIDS Strategy that includes a focus on law reform that may hold promise in achieving goals that were missed in 2020.

of individuals and the rol-out of, and participation in, interventions. ${ }^{1-3}$ How best to use criminal law and human rights protections to shape behaviour in a pandemic has been hotly debated not just in HIV but in COVID19, Ebola, tuberculosis and beyond. ${ }^{4-7}$ At the core of these tensions are questions about whether criminalising behaviour helps public health and whether rights-supporting policies distract or enhance public health interventions-questions particularly acute for populations highly impacted by the HIV pandemic.

During the last decade, biomedical science in HIV has progressed rapidly, with 
breakthroughs in prevention and treatment. ${ }^{8}$ Yet, the global HIV response has seen highly differential success between countries. While AIDS deaths and new infections fell, according to the United Nations (UN) estimates, only 26 countries are on track to achieve the global goal of a $90 \%$ reduction in AIDS-related mortality by 2030 , and only 23 countries are on track to reduce new HIV infections by $90 \% .^{10}$

Globally, at the end of 2020, an estimated $84 \%$ of people living with HIV (PLHIV) knew their HIV status. ${ }^{11}$ About 27.5 million PLHIV were accessing treatment-a number that has more than tripled since 2010. In total, $66 \%$ of all PLHIV knew their status, were on antiretroviral treatment and had suppressed virus, which improves health and prevents both mortality and HIV transmission-a remarkable accomplishment but well short of the goal for 2020.

Countries across different regions, income levels and epidemic profiles have seen success. ${ }^{12}$ For example, in Thailand-a middle-income country where $1 \%$ of the population was living with HIV in 2020-new infections have fallen by two-thirds since 2010 as $94 \%$ of all PLHIV came to know their status and over three-quarters achieved viral suppression. Germany, a high-income country with a $0.1 \%$ HIV prevalence level, had similar levels of viral suppression to Thailand. South Africa, a middle-income country with the largest HIV epidemic in the world, had similarly high 92\% knowledge of HIV status but lower viral suppression of just $66 \%$ of all PLHIV as it struggled to keep people on treatment. The USA, the world's wealthiest nation with a concentrated HIV epidemic, had lower rates than all three. And at the other end of the spectrum, in more than a quarter of countries, less than $50 \%$ of PLHIV had suppressed virus in $2019 .{ }^{10}$ These include wealthier countries like Russia and lower-middle-income countries like Pakistan, where only an estimated $22 \%$ of PLHIV know their status and new infections are rising. In Jamaica and Angola, AIDS deaths are rising amidst low rates of viral suppression; just $33 \%$ of Jamaicans living with HIV were estimated to have suppressed virus. ${ }^{12}$

Law is one of several epidemiological, social, economic and political factors driving differential success. As the Global Commission on HIV and the Law found, 'the legal environment can play a powerful role in the wellbeing of people living with HIV and those vulnerable to HIV.' ${ }^{13}$ Law is particularly powerful when it comes to key populations experiencing higher HIV rates and lower access to services, including gay men and other men who have sex with men, sex workers, transgender people and people who inject drugs. ${ }^{14}$ Laws that subject key populations to arrest, prosecution and imprisonment for engaging in behaviours governments deem undesirable are widespread. Meanwhile, many countries have what we call rights-protective and genderprotective laws, which establish independent rights institutions, combat gender-based violence and outlaw discrimination.
The UN-adopted Global AIDS Strategy ending in 2021 centred 90-90-90 targets ${ }^{\mathrm{i}}$ on HIV testing and treatment, aiming for $90 \%$ of PLHIV to know their status, $90 \%$ of these to be on treatment and $90 \%$ of these to have achieved viral suppression-resulting to a total of $73 \%$ of all PLHIV to have suppressed virus by $2020{ }^{15}$ A new strategy for the 2022-2027 period specifically focuses on removal of criminalising laws alongside expansion of efforts to combat stigma, gender-based violence and human rights violations. ${ }^{16}$

This paper explores whether countries that pursued a criminalisation approach achieved better or worse outcomes under the 90-90-90 targets than those with a less criminalised environment. We further ask whether countries that adopted rights-protective and genderprotective laws and policies ended this period with better HIV outcomes or not. We do so using a new dataset that has coded HIV-related laws and policies for 194 countries to enable cross-national comparative analysis. ${ }^{17}$

Since long before HIV, through to the present, governments have argued that criminalising socially undesired behaviour like same-sex sexual acts, sex work and drug use helps prevent disease and change behaviour. ${ }^{18-20}$ Though scholars seldom go that far, some have argued against decriminalisation on the grounds that it could have negative health implications. ${ }^{21}$ Yet, a wider normative, theoretical and empirical literature finds criminalisation has a negative effect on HIV services and on health outcomes for key populations. ${ }^{1422-27}$ Empirical work in both high-income and lower-income settings has included population-specific qualitative studies in specific countries, ${ }^{28-31}$ modelling, ${ }^{32}$ ecological studies in particular regions ${ }^{33} 34$ and increasingly sophisticated quantitative efforts in multicountry samples. ${ }^{35}$

Here, we explore the question of whether criminalising countries saw better or worse HIV outcomes at the end of the last Global AIDS Strategy using a new dataset of laws and policies for the 194 countries that are signatories to the global AIDS commitments. The HIV Policy Lab dataset provides cross-nationally comparative coded data. ${ }^{17}$ This enables us to look at three aspects in global perspective: same-sex, sex work and drug use/possession criminalisation. We explore all three simultaneously and in combination, as well as rights-protective and gender-protective laws. Data are gathered through analysis of legal texts, official reporting to UN through the Global AIDS Monitoring framework and meta-analysis of additional public sources including analysis by International Lesbian, Gay, Bisexual, Trans and Intersex Association (ILGA), the Global Network of Sex Work Projects and International Drug Policy Consortium as described by Kavanagh et al. ${ }^{17}$

Around the world, same-sex, sex work and drug use criminalisation is widespread but varied, cutting across

${ }^{\mathrm{i}} 90-90-90$ targets are $90 \%$ of all people living with HIV know their HIV status, $90 \%$ of those people are on sustained antiretroviral treatment and $90 \%$ of those on treatment have viral suppression. 
income and geography. As of 2020, only $20 \%$ of countries fully criminalise all three aspects explored here, but every country at least partially criminalises one or more; $21 \%$ and $53 \%$ fully criminalise one or two, respectively. Meanwhile, $23 \%$ of countries have non-discrimination protections that cover sexual orientation, gender identity and HIV status, while $39 \%$ have independent human rights institutions, and $79 \%$ have enforceable genderbased violence laws.

\section{ASSESSING LAWS AND PANDEMIC RESPONSE PROGRESS}

The 90-90-90 targets, set in 2014 to be achieved by 2020, give us a clear, globally agreed metric with which to compare the success of national AIDS responses. Knowledge of status is a critical entry point for differential biomedical and behavioural options for prevention as well as treatment. Viral suppression is a key indicator of the accessibility, acceptability and quality of HIV services. Criminalisation has been linked to a variety of factors, from mistrust of authorities to stigma from providers, that leads to avoidance of medical services, avoidance of diagnosis and challenges starting and staying on HIV treatment. ${ }^{24} 2935$ Whether those resulted in measurable global differences in the overall success of countries' AIDS response-particularly during this period of global focus on 90-90-90 targets-is not clear.

We use a cross-sectional dataset to compare the relative success of criminalising countries to those with a less punitive legal approach. Our outcome variables for each country are the percent of all PLHIV who know their status and the percent of all PLHIV who are virally suppressed, both from data released July 2020 by the Joint United Nations Programme on HIV/AIDS. ${ }^{36}$

We test each of four variables of interest related to criminalisation from the HIV Policy Lab against these HIV service outcomes. Same-sex criminalisation codes whether the laws of a given country criminalise consensual same-sex sex acts and whether the country actively prosecutes people under these laws. The variable on sex work codes whether national law criminalises the buying, selling and organising of sex work. The drug use variable codes whether national laws criminalise the use or possession of small amounts of drugs, including opioids, for personal consumption. Each of these variables is coded on a three-part scale of criminalised, partially criminalised or not criminalised. This range is important since, while seeking the benefits of quantitative coding, we are conscious of work on the complex relationship between criminalisation and health. We drop the few observations where countries' laws meaningfully changed in this period. We also test a fourth variable that combines all three of these into one variable representing a range of overall criminalisation of key population-linked behaviour from none to fully criminalised. Descriptive statistics and data on countries' policy adoption status for each variable are provided in online supplemental appendix 1. Full data, including policy adoption maps and the codebook, are available at hivpolicylab.org.

We use fractional logistic regression models with robust SEs to investigate the association between HIV service outcomes and explanatory policy variables. Each of our individual policy variables (same-sex sex, drug use and sex work) as well as our combination variable is tested separately against our two HIV service outcomes. Fractional logistic regressions with robust $\mathrm{SE}$ are suitable for variables whose values vary from 0 to 1 or as percentages like in our setting and provide consistent estimates. ${ }^{37}$ We subsequently estimate the marginal average effects interpreted as the amount of change in the outcome induced by changing the law status from 'not adopted' to 'fully adopted'. When explanatory variables are logtransformed, the marginal average effects are interpreted as the amount of change in the outcome induced by a $1 \%$ increase in the log-transformed explanatory variable.

In a second analysis, we explore whether countries with rights-protective and gender-protective laws like those described in the new Global AIDS Strategy have achieved better HIV outcomes during the previous strategy period. A non-discrimination variable codes whether countries have legally enshrined protections from discrimination based on sexual orientation, gender identity and HIV status. Human rights institutions explores which countries have independent national rights bodies to which PLHIV and key populations report abuse and discrimination that meet the conditions set out in the UN Paris Principles. ${ }^{38}$ A gender-based violence variable indicates whether the country has explicit laws tackling domestic or gender-based violence with enforceable penalties. Each of these variables was tested separately against our HIV service variables to explore whether countries that enshrine these protections have seen better or worse HIV service outcomes.

In a multivariable analysis for each policy variable, we add control for basic confounders. These include relative wealth and spending on health in the country-log health expenditure per capita, $2019^{39}$ — which has a theoretical connection to success in HIV service provision and a significant association in our data. We also control for the relative size of the HIV epidemic in a country to account for the distinct but significant challenges reaching high coverage in both high-prevalence and low-prevalence settings. We are using a log baseline 2014 prevalence, ${ }^{12}$ the year the 90-90-90 goals were set.

While we cannot make causal inferences from this data, we can understand the following basic question: did countries with criminalising or rights/gender-protecting laws achieve better, worse or roughly the same outcomes over this period compared with those who did not?

\section{EVIDENCE ON THE AIDS RESPONSE UNDER CRIMINALISATION AND UNDER RIGHTS PROTECTION}

In countries that criminalise same-sex sexual relations, sex work and/or drug use, a smaller portion of PLHIV 
$\%$ of all PLHIV

who know their status

Same Sex NonCriminalization

Sex Work NonCriminalization

Drug Use NonCriminalization

Criminalization Composite

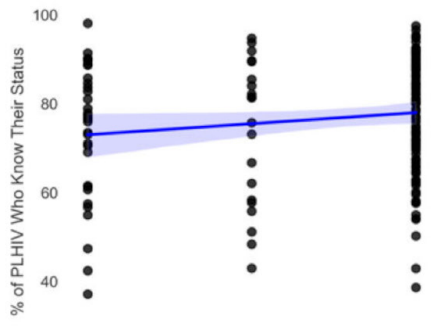

20 Criminalization
Same Sex Soriminalization
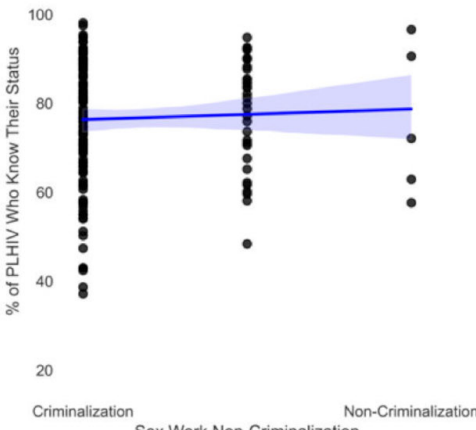

Sex Work Non-Criminalization

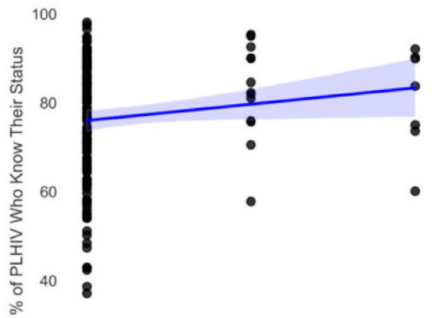

Non-Criminalization

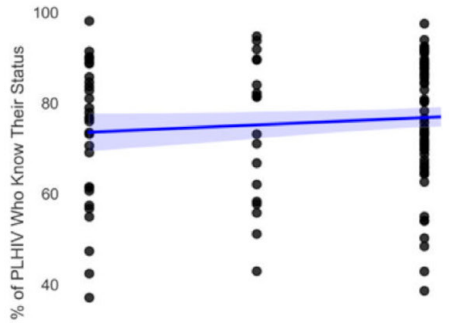

Criminalization

Criminalization Composite ${ }^{\text {Non-Criminalization }}$
$\%$ of PLIHIV

with suppressed viral load
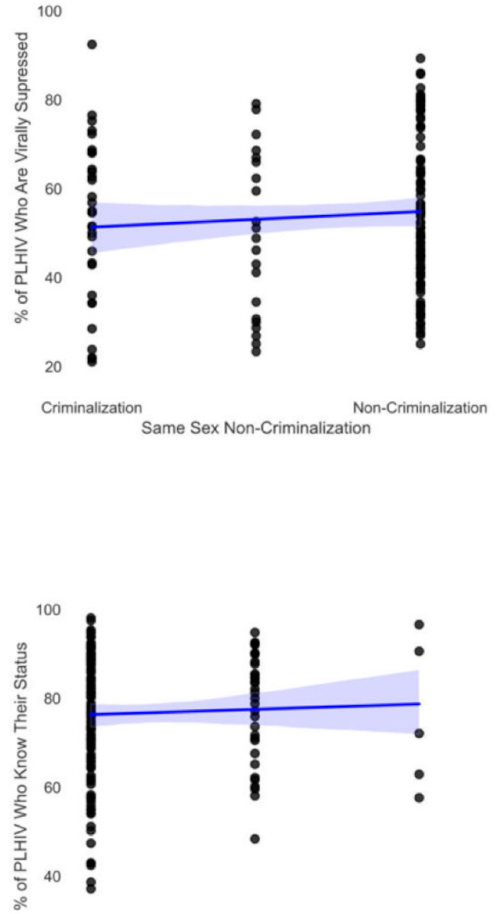

Criminalization Non-Criminalization
Sex Work Non-Criminalization

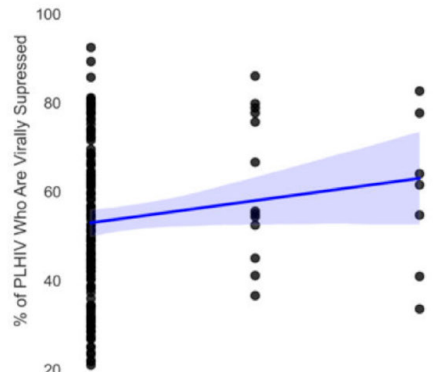

Criminalization Non-Criminalization
Drug Use Non-Criminalization

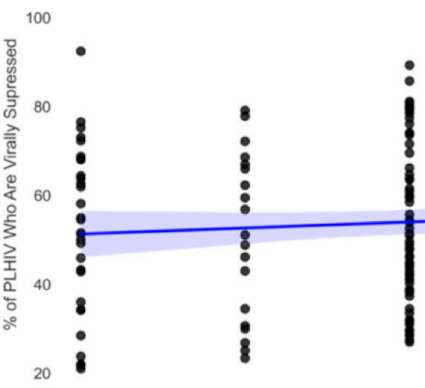

Criminalization Non-Criminalization

Figure 1 HIV service outcomes under criminalisation. PLHIV, people living with HIV. 
Table 1 Unadjusted and adjusted marginal average effect estimates of punitive laws on HIV service outcomes

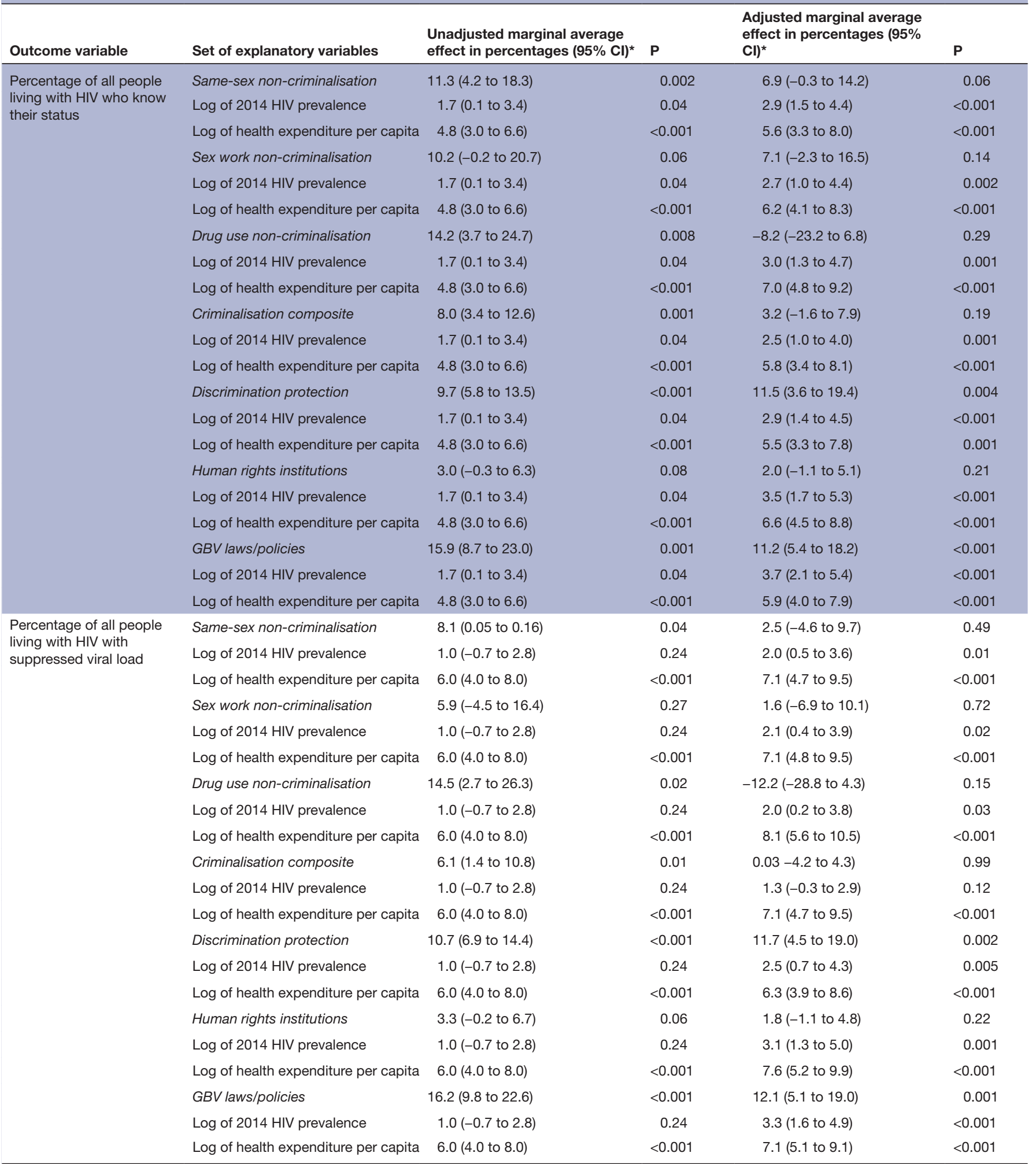

*Estimates and inferences from fractional logistic regression models with robust SEs. The adjusted model includes the policy variable, prevalence and health expenditure modelled together.

GBV, gender-based violence.

knew their HIV status and had suppressed virus compared with countries without criminalising laws. These relationships are shown in figure 1, with coefficients and details in table 1. Countries that criminalise same-sex sex had an unadjusted average of $11.3 \%$ ( $\mathrm{p}=0.002,95 \%$ CI: 4.2 to 18.3) lower knowledge of HIV status among PLHIV. In countries that criminalise sex work, $10.2 \%(\mathrm{p}=0.06,95 \%$ CI: -0.2 to 20.7) fewer of those living with HIV know their 
status, and where drug use is criminalised, it is $14.2 \%$ ( $p=0.008,95 \%$ CI: 3.7 to 24.7 ) lower. Taken together in our composite measure that combines law in these three areas, the model shows that if trends held across countries, a theoretical country with no criminalisation across all three would have as much as $24.0 \%$ higher knowledge of status than one with a fully criminalised environment on all three $(p=0.001$; note that the coefficient is $\times 3$ for fully criminalised).

Countries with criminalised legal environments had lower rates of viral suppression compared with those with non-criminalised environments. Rates of viral suppression were, in an unadjusted average, 8.1\% ( $\mathrm{p}=0.04,95 \%$ CI: 0.05 to 0.16 ) lower in countries that criminalise same-sex sexual relations, $5.9 \%(p=0.27,95 \% \mathrm{CI}:-4.5$ to 16.4) lower under sex work criminalisation and $14.5 \%$ ( $p=0.02,95 \%$ CI: 2.7 to 26.3 ) lower when drug use was criminalised. Taken together in our composite variable, the difference between a theoretically fully criminalised and fully non-criminalised country would be as much as an $18.3 \%(p=0.01)$ difference in viral suppression.
After controlling for HIV prevalence and health expenditure per capita, same-sex criminalisation was significantly associated with better knowledge of HIV status. The other variables did not maintain statistical significance-which was not surprising for a cross-sectional global dataset where power is limited by a sample size of 194 countries and where strongly correlated factors like HIV prevalence are in the analysis. Further analysis is worthwhile in the future when a longitudinal dataset with a larger sample size can be created and where broader epidemiological measures like incidence changes can be explored.

A higher portion of PLHIV knew their HIV status in countries with non-discrimination protections $(9.7 \%$, $\mathrm{p}=<0.001,95 \%$ CI: 5.8 to 13.5$)$, independent human rights institutions $(3.0 \%, \mathrm{p}=0.08,95 \% \mathrm{CI}:-0.3$ to 6.3$)$ or explicit gender-based violence laws $(15.9 \%, \mathrm{p}=0.001$, 95\% CI: 8.7 to 23.0$)$. Figure 2 shows these relationships. Higher viral suppression rates were also significantly associated with non-discrimination protections $(10.7 \%$, $\mathrm{p}=<0.001,95 \%$ CI: 6.9 to 14.4$)$, independent human

Figure 2 HIV service outcomes under rights and gender protection. GBV, gender-based violence. 
rights institutions $(3.3 \%, \mathrm{p}=0.06,95 \%$ CI: -0.2 to 6.7$)$ and gender-based violence laws $(16.2 \%, \mathrm{p}=<0.001,95 \%$ CI: 9.8 to 22.6). Non-discrimination and gender-based violence laws were significant even after controlling for prevalence and spending.

There are a number of important limitations to this analysis. First, this is an ecological study and is not sufficient to identify causal mechanisms. Ecological fallacies and confounding factors cannot be discounted. One strength of this analysis is a unique global dataset addressing countries in all regions and income levelsallowing us to avoid common problems of systematically missing but theoretically important countries that challenge cross-national social science. ${ }^{40}$ Yet, while multilevel data would be desirable to study HIV outcomes, no such global dataset exists. ${ }^{41}$ In addition, we face all of the common problems of measuring law, including that our tripartite coding rules cannot capture enforcement or subtle differences between countries that may be meaningful.

As such, the causal effect of criminalisation and protective laws remains an important topic of future research. Longitudinal studies with panel data could, in the future, explore more deeply the association between laws and HIV outcomes by investigating whether and in what time frame HIV outcomes change in countries that change criminalising or protective laws. Additionally, quantitative data analysis could be paired with qualitative research to elucidate causal mechanisms through which the legal environment impacts healthcare access for people living with and at risk of HIV. In addition, a number of unmeasured confounders deserve further exploration. HIV programme funding data are not reliably available in a global dataset, for example. Therefore, the question of whether increased funding-particularly to community-led HIV services-can compensate for problematic legal environments is an important question for future research.

\section{CONCLUSION}

At the end of a 5-year strategy in which countries around the world focused their AIDS response on 90-90-90 targets to reaching PLHIV with testing and treatment services, countries that have adopted a criminalising approach to key populations saw less success than those that chose not to criminalise. Where same-sex sex, sex work and drug use were criminalised, a smaller portion of PLHIV knew their status, and fewer had suppressed virus. Meanwhile, where protective laws have been adopted that advance nondiscrimination, human rights institutions and responses to gender-based violence, countries have done better on the 90-90-90 goals. These relationships were observable by using a global database of comparable cross-national data about laws and policies. As this resource grows and longitudinal data become available, studies with greater causal identification will become increasingly possible.
In the last year, laws went into effect in Angola removing criminalisation of same-sex sexual acts while enacting non-discrimination protections on the basis of sexual orientation; in the US state of Oregon decriminalising personal drug possession; and in Northern Territory, Australia, decriminalising sex work. This study suggests these may well be positive moves for public health, ripe for further study.

This study finds little support for the argument that criminalising behaviour among marginalised people in a pandemic results in positive outcomes. On the other hand, it suggests protecting human rights and addressing gender-based violence may help build an environment in which biomedical interventions are more successful. With global goals to reduce HIV incidence and mortality unmet-and in a context of intersecting pandemicsgreater consideration should be given to law reform as a critical pandemic intervention.

\section{Author affiliations}

${ }^{1}$ Department of International Health, Georgetown University, Washington, District of Columbia, USA

${ }^{2} 0$ 'Neill Institute for National and Global Health Law, Georgetown University, Washington, District of Columbia, USA

${ }^{3}$ Department of Health Data Science, University of Liverpool, Liverpool, UK ${ }^{4}$ Department of Infectious Disease Epidemiology, London School of Hygiene and Tropical Medicine, London, UK

${ }^{5}$ Society for Democratic Rights, New Delhi, India

${ }^{6}$ Talus Analytics, Boulder, Colorado, USA

${ }^{7}$ Strategic Information Department, Joint United Nations Programme on HIV/AIDS (UNAIDS), Geneve, Switzerland

${ }^{8}$ Center for Global Health Science and Security, Georgetown University, Washington, District of Columbia, USA

Twitter Matthew M Kavanagh @MMKavanagh, Kashish Aneja @KashishAneja_, Mara Pillinger @mplngr, Ngozi A Erondu @udnore, Taavi Erkkola @Taavie1 and Ellie Graeden @elliegraeden

Acknowledgements The authors particularly recognise ILGA, the Global Network of Sex Work Projects and International Drug Policy Consortium - partners in the HIV Policy Lab who contributed key policy data that formed part of the dataset for this project.

Contributors All authors reviewed the manuscript, provided edits and approved the final version. MK wrote the overall draft. SCA and MJ conducted statistical analysis. MP, KA, TE, AC and EG collected and coded the data and conducted law and policy analysis.

Funding This study was funded by US Agency for International Development and Joint United Nations Programme on HIV/AIDS.

Competing interests None declared.

Patient consent for publication Not required.

Provenance and peer review Not commissioned; externally peer reviewed.

Data availability statement Data are available in a public, open access repository at www.HIVPolicyLab.org

Supplemental material This content has been supplied by the author(s). It has not been vetted by BMJ Publishing Group Limited (BMJ) and may not have been peer-reviewed. Any opinions or recommendations discussed are solely those of the author(s) and are not endorsed by BMJ. BMJ disclaims all liability and responsibility arising from any reliance placed on the content. Where the content includes any translated material, BMJ does not warrant the accuracy and reliability of the translations (including but not limited to local regulations, clinical guidelines, terminology, drug names and drug dosages), and is not responsible for any error and/or omissions arising from translation and adaptation or otherwise.

Open access This is an open access article distributed in accordance with the Creative Commons Attribution Non Commercial (CC BY-NC 4.0) license, which 
permits others to distribute, remix, adapt, build upon this work non-commercially, and license their derivative works on different terms, provided the original work is properly cited, appropriate credit is given, any changes made indicated, and the use is non-commercial. See: http://creativecommons.org/licenses/by-nc/4.0/.

\section{ORCID iDs}

Matthew M Kavanagh http://orcid.org/0000-0003-1751-4828

Ngozi A Erondu http://orcid.org/0000-0003-0268-6838

Ellie Graeden http://orcid.org/0000-0002-1265-9756

\section{REFERENCES}

1 Grover A. Report of the special Rapporteur on the right of everyone to the enjoyment of the highest attainable standard of physical and mental health. Geneva: United Nations Office of the High Commissioner, 2011.

2 Avafia T, Konstantinov B, Esom K. A rights-based response to COVID-19: lessons learned from HIV and TB epidemics. Health and Human Rights Journal 2020.

3 Gostin LO, Monahan JT, Kaldor J, et al. The legal determinants of health: harnessing the power of law for global health and sustainable development. Lancet 2019;393:1857-910.

4 Eba PM. Ebola and human rights in West Africa. The Lancet 2014;384:2091-3.

5 Sekalala S, Forman L, Habibi R, et al. Health and human rights are inextricably linked in the COVID-19 response. BMJ Glob Health 2020;5:e003359.

6 Kavanagh MM, Gostin LO, Stephens J. Tuberculosis, human rights, and law reform: addressing the lack of progress in the global tuberculosis response. PLoS Med 2020;17:e1003324.

7 Amadasun S. COVID-19 palaver: ending rights violations of vulnerable groups in Africa. World Dev 2020;134:105054.

8 Abdool Karim SS. HIV-1 Epidemic Control - Insights from Test-andTreat Trials. N Engl J Med 2019;381:286-8.

9 Fauci AS, Lane HC. Four decades of HIV/AIDS - much accomplished, much to do. N Engl J Med Overseas Ed 2020;383:1-4

10 United Nations. Addressing inequalities and getting back on track to end AIDS by 2030: report of the Secretary-General. New York: UN 2021. https://hlm2021aids.unaids.org/sg-report/

11 UNAIDS. Unaids global AIDS update 2021: confronting inequalities. Geneva: UNAIDS, 2021. https://www.unaids.org/en/resources/ documents/2021/2021-global-aids-update

12 AIDSinfo U, 2021. Available: http://aidsinfo.unaids.org/ [Accessed 14 Jul 2021].

13 Global Commission on HIV and the Law. HIV and the Law: Risks, Rights \& Health. New York: United Nations Development Program, 2012. https://hivlawcommission.org/

14 UNAIDS. Hiv prevention among key populations. Geneva: UNAIDS, 2016. http://www.unaids.org/en/resources/presscentre/ featurestories/2016/november/20161121_keypops

15 UNAIDS. 90-90-90: an ambitious treatment target to help end the AIDS epidemic, 2014. Available: https://www.unaids.org/sites/ default/files/media_asset/90-90-90_en.pdf [Accessed 14 May 2020].

16 UNAIDS. Global AIDS strategy 2021-2026: end inequalities. End AIDS 2021 https://www.unaids.org/en/Global-AIDS-Strategy-20212026

17 Kavanagh MM, Graeden E, Pillinger M, et al. Understanding and comparing HIV-related law and policy environments: cross-national data and accountability for the global AIDS response. BMJ Glob Health 2020;5:e003695.

18 McKay RA. Before HIV. In: The Routledge history of disease. Routledge, 2016.
19 Whitehead J. Sir Keir Starmer says he opposes relaxing drugs laws and insists he is 'proud' to be patriotic. iNews, 2021. Available: https://inews.co.uk/news/politics/keir-starmer-drug-liberalisationlaws-health-crime-881386 [Accessed 13 May 2021].

20 Hayes-Smith R, Shekarkhar Z. Why is prostitution criminalized? an alternative viewpoint on the construction of sex work. Contemporary Justice Review 2010;13:43-55.

21 Farley M. "Bad for the body, bad for the heart": Prostitution harms women even if legalized or decriminalized. Violence Against Women 2004;10:1087-125.

22 Makofane K, Beck J, Lubensky M, et al. Homophobic legislation and its impact on human security. African Security Review 2014;23:186-95.

23 Adebisi YA, Alaran AJ, Akinokun RT, et al. Sex workers should not be forgotten in Africa's COVID-19 response. Am J Trop Med Hyg 2020;103:1780-2.

24 Arreola S, Santos G-M, Beck J, et al. Sexual stigma, criminalization, investment, and access to HIV services among men who have sex with men worldwide. AIDS Behav 2015;19:227-34.

25 Beyrer C, Baral SD, Collins C, et al. The global response to HIV in men who have sex with men. The Lancet 2016;388:198-206.

26 Beyrer C, Crago A-L, Bekker L-G, et al. An action agenda for HIV and sex workers. Lancet 2015;385:287-301.

27 Strathdee SA, Beletsky L, Kerr T. Hiv, drugs and the legal environment. Int J Drug Policy 2015;26 Suppl 1:S27-32.

28 Trapence G, Collins C, Avrett S, et al. From personal survival to public health: community leadership by men who have sex with men in the response to HIV. The Lancet 2012;380:400-10.

29 Poteat T, Diouf D, Drame FM, et al. Hiv risk among MSM in Senegal: a qualitative rapid assessment of the impact of enforcing laws that criminalize same sex practices. PLoS One 2011;6:e28760.

30 Sarang A, Rhodes T, Sheon N. Systemic barriers accessing HIV treatment among people who inject drugs in Russia: a qualitative study. Health Policy Plan 2013;28:681-91.

31 King R, Sebyala Z, Ogwal M, et al. How men who have sex with men experience HIV health services in Kampala, Uganda. BMJ Glob Health 2020:5:e001901.

32 Shannon K, Strathdee SA, Goldenberg SM, et al. Global epidemiology of HIV among female sex workers: influence of structural determinants. The Lancet 2015;385:55-71.

33 Reeves A, Steele S, Stuckler D, et al. National sex work policy and HIV prevalence among sex workers: an ecological regression analysis of 27 European countries. Lancet HIV 2017;4:e134-40.

34 Lyons C, Diouf D, Rwema JO. Utilizing individual level data to assess the relationship between prevalent HIV infection and punitive same sex policies and legal barriers across 10 countries in sub-Saharan Africa. Journal of The International AIDS Society 2020:102.

35 Lyons CE, Schwartz SR, Murray SM, et al. The role of sex work laws and stigmas in increasing HIV risks among sex workers. Nat Commun 2020:11:1-10.

36 UNAIDS. Prevailing against pandemics. Geneva: UNAIDS, 2020. https://aidstargets2025.unaids.org/

37 Papke LE, Wooldridge JM. Econometric methods for fractional response variables with an application to $401(\mathrm{k})$ plan participation rates. J Appl Econ 1996;11:619-32.

38 Un office of the high commissioner for human rights. principles relating to the status of national institutions. Geneva: : United Nations 1993 https://www.ohchr.org/en/professionalinterest/pages/ statusofnationalinstitutions.aspx

39 Bank W. Indicators WD, 2020. Available: https://databank. worldbank.org/source/world-development-indicators [Accessed 14 May 2021]

40 Ross M. Is democracy good for the poor? Am J Pol Sci 2006;50:860-74.

41 Boily M-C, Shannon K, law C. Criminal law, sex work, HIV: need for multi-level research. Lancet HIV 2017;4:e98-9. 